\title{
ETAT: Expository Text Analysis Tool
}

\author{
EDUARDO VIDAL-ABARCA, HÉCTOR REYES, RAMIRO GILABERT, \\ JAVIER CALPE, and EMILIO SORIA \\ University of Valencia, Valencia, Spain \\ and \\ ARTHUR C. GRAESSER \\ University of Memphis, Memphis, Tennessee
}

\begin{abstract}
Qualitative methods that analyze the coherence of expository texts not only are time consuming, but also present challenges in collecting data on coding reliability. We describe software that analyzes expository texts more rapidly and produces a notable level of objectivity. ETAT (Expository Text Analysis Tool) analyzes the coherence of expository texts. ETAT adopts a symbolic representational system, known as conceptual graph structures. ETAT follows three steps: segmentation of a text into nodes, classification of the unidentified nodes, and linking the nodes with relational arcs. ETAT automatically constructs a graph in the form of nodes and their interrelationships, along with various attendant statistics and information about noninterrelated, isolated nodes. ETAT was developed in Java, so it is compatible with virtually all computer systems.
\end{abstract}

Many disciplines, such as linguistics, cognitive psychology, discourse processes, and artificial intelligence, have traditionally been interested in the analysis of written texts (Britton \& Black, 1985; Coulthard, 1994, 1997; Kintsch, 1974, 1998; Meyer, 1975; Polanyi, 1988; Sanders \& van Wijk, 1996; Schank \& Abelson, 1977). Expository texts have received a large amount of attention because they are an important medium for the acquisition of new knowledge in instructional settings (Linn, Songer, \& Eylon, 1996; Wineburg, 1996). The tool that we describe, Expository Text Analysis Tool (ETAT), helps researchers and textbook editors analyze the coherence of expository texts both objectively and rapidly.

The text analysis procedures can be classified into two groups: those useful for practical applications and those useful for theoretical investigations. In the former group, the texts are analyzed for their coherence and comprehensibility. The goal is to find the text characteristics that might prevent the reader from forming a coherent representation of the concepts therein. Once these features are detected, the investigator can introduce changes to the text and test the impact of the changes on comprehension and memory (Beck, McKeown, Sinatra, \& Loxterman, 1991; Britton \& Gülgöz, 1991; McNamara, Kintsch, Songer, \& Kintsch, 1996; Vidal-Abarca \& Sanjosé, 1998). When formulating the changes, it is important to do so in a principled fashion, rather than in an intuitive, ad hoc

A copy of ETAT can be obtained upon request to the first author. It will be sent as a CD via ordinary mail and C.O.D. at no additional cost. Correspondence concerning this article should be addressed to E. VidalAbarca, Department of Educational Psychology, University of Valencia, Avda. Blasco Ibáñez, 21, 46010 Valencia, Spain (e-mail: eduardo.vidalabarca@uv.es). fashion. Therefore, it is important to ground the changes in a theory of knowledge representation.

The theoretical objective is to represent the semantic and conceptual information suggested by the text (Gernsbacher, 1997; Graesser, Singer, \& Trabasso, 1994; Kintsch, 1998; Kintsch \& van Dijk, 1978; Rumelhart, 1980; van Dijk \& Kintsch 1983; Zwaan, Langston, \& Graesser, 1995). These procedures evolved from the cognitive psychology of the 1970s and were closely associated with models of text processing. The initial analyses focused on the structure of simple narrative texts. Researchers devised story grammars that specified the categorization of clauses into events and states and a set of rules for combining and sequencing the constituents (Mandler \& Johnson, 1977; Rumelhart, 1977; Stein \& Glenn, 1979; Thorndyke, 1977). Inspired by story grammars, Meyer (1975, 1985 ) developed a procedure to analyze expository prose structure. Ideally, a grammar could handle any text in its class. In practice, however, the grammars either have been incomplete or have successfully handled a narrow niche of text genres.

Kintsch and van Dijk's (1978) text-processing model pursued a somewhat different approach to text analysis. These authors developed a proposition-based text-processing model and a computer program that implemented the model (Miller \& Kintsch, 1980). Their model produced a representation of semantic structure for any class of texts. This computational program has been used by Britton and Gülgöz (1991) and Vidal-Abarca, Martínez, and Gilabert (2000) to analyze the problems in expository text comprehension. Although the Kintsch and van Dijk model is both general and detailed, its application presents a few practical challenges. The basic unit of textual analysis (i.e., atomic propositions) is fine-grained, so it 
takes an enormous amount of time to apply it to any text of reasonable length. For instance, the sentence Purplish blood tends to lack oxygen can be expressed as the following three propositions:

$$
\begin{array}{ll}
\text { P1 } & \text { TEND [P2, P3] } \\
\text { P2 } & \text { PURPLISH [BLOOD] } \\
\text { P3 } & \text { LACK [P2, OXYGEN]. }
\end{array}
$$

What is needed is a more macro unit of analysis that corresponds to sentences or clauses. Another shortcoming of the Kintsch and van Dijk (1978) computerized version is that its primary method of linking propositions consists of argument overlap (i.e., common noun-phrase referents among propositions). This method provides an incomplete foundation for establishing coherence, because it ignores many other conceptual dimensions that are known to influence coherence, such as temporality, causality, spatiality, and goals (Zwaan et al., 1995).

Graesser and his colleagues (Graesser 1981; Graesser \& Goodman, 1985a, 1985b; Graesser, Gordon, \& Brainerd, 1992; Graesser, Wiemer-Hastings, \& Wiemer-Hastings, 2001) present a more complete set of relations that potentially provide coherence in text. Graesser proposed a common system to represent both knowledge structures and text information. The system represents the explicit information of a text as well as the inferences that the reader should make in order to connect the individual text units. The information is represented as a network of labeled statement nodes that are interrelated by labeled, directed arcs. The final network is called a conceptual graph structure (CGS). There are principled procedures that segment the text into statement nodes, classify the nodes into theoretical categories (e.g., events, states, processes, goals, concepts, and style specifications), and interrelate the nodes by directed relational arcs in different categories. The system can be applied to any type of text via an objective procedure that can be learned in a few hours.

There are a number of advantages to using Graesser's system: It is general, it is detailed, it uses analysis units of a greater length than the propositions, and it has semantic criteria for assigning nodes and arcs into different categories. Moreover, the representational system has directly or indirectly been validated as being psychologically plausible in numerous empirical studies of reading comprehension, memory, summarization, and question answering (Graesser \& Hemphill, 1991; Graesser, Lang, \& Roberts, 1991; Zwaan et al., 1995; Zwaan, Magliano, \& Graesser, 1994). However, it should be noted that alternative CGS representations could be used as a substitute for Graesser's system (Golden, 1998; Trabasso, van den Broek, \& Suh, 1989). In this sense, ETAT should be viewed as a generic tool.

\section{CONCEPTUAL GRAPH STRUCTURES}

Constructing the network of nodes called CGSs involves three major steps (see Graesser \& Goodman, 1985a, for a more detailed description). The first step segments information into statement nodes. A statement node contains a predicate and one or more arguments. For example, the sentence During the 19th century Russia was kept on the sidelines of the revolutions that had transformed socially the rest of Europe can be divided into four statement nodes:

1. Russia was kept on the sidelines of the revolutions at time $T$,

2. Time $\mathrm{T}$ was the 19th century,

3. Revolutions had transformed the rest of Europe,

4. Transformation was social.

The second step assigns each node to a node category. There have been slight changes in the formulation of the categories as the system has been developed, although the following have always been maintained: state, event, goal, and style.

State. This is an ongoing characteristic that remains unchanged within a relevant time frame. There may be physical, social, or psychological states. Nodes 1 and 2 are states.

Event. This refers to a state change that occurs within a relevant time frame. Node 3 is an example of an event.

Goal. This is a state or an event that an agent wants to achieve. The statement node "The Czars controlled the power" is a goal.

Style. This refers to a qualitative manner or intensity in which an event or a goal unfolds. It is a modifier, such as Node 4.

The third step is to interrelate the nodes via labeled, directed arcs in different categories. The arc categories that have frequently been adopted are reason, initiate, consequence, property, and manner. Each arc category has specific constraints as to which node categories are to be connected, and each has a designated direction. For instance, Nodes 2 and 3, mentioned above, are a property of Node 1. This arc category is defined as follows:

Property: relationship between $<$ argument of a node $>$ and $<$ state $>$.

Part of the statement nodes represented in a CGS come from the text being analyzed. The remaining nodes come from the inferential activity on the part of the reader. To obtain the inferential nodes, a question/answer method has been applied in previous projects. Thus, the final CGS represents the knowledge structure that the reader may ideally construct when reading the text. However, in the case of expository texts, readers make comparatively few knowledge-based inferences, because the information is unfamiliar to most readers (Graesser, 1981). Therefore, it is a reasonable goal to use the CGSs to represent the explicit text information.

\section{ETAT \\ A Tool to Analyze Expository Text Information}

ETAT is a tool designed to analyze the semantic and conceptual relationships between explicit text ideas. It 
was inspired by the CGS representations developed by Graesser and his colleagues. The main difference between ETAT and the CGS procedure is that the latter represents statement nodes coming from the text and also from the reader's inferential activity, whereas ETAT represents only the information in the text. There are a few other differences, which will be explained as we go.

\section{Analysis Procedure}

ETAT aids the analysis of text information according to the three steps (node segmentation, node classification, and node connection) described for the construction of the CGSs. However, for each step, some changes have been introduced to simplify the analysis and adapt the tool to any expository text, including lengthy texts.

Node segmentation. In the first step, the text is divided into nodes. A node is defined as a complete sentence. A complete sentence may contain a main clause and several subordinate clauses. It is the main clause that is regarded as the point of the sentence, so the main clause is what guides the subsequent classification step. Therefore, the complexity of the nodes in ETAT is far greater than that in CGS. This simplifies the chore of segmenting a text, given that phrases of a text are complete sentences and not unusually long. There are a few exceptions, however, where clauses within a sentence are segregated. When the sentence contains coordinate constituents, it is necessary to split the sentence into distinct nodes.

To illustrate this point, consider once again the example sentence During the 19th century Russia was kept on the sidelines of the revolutions that had transformed socially the rest of Europe. This sentence had four nodes in the CGS system, but just one single node in ETAT. However, the sentence The middle class was practically nonexistent, and the minority proletariat pushed for revolution contains two coordinate sentences. Therefore, it would be split into two nodes: (1) the middle class was practically nonexistent, and (2) the minority proletariat pushed for revolution. In the case of if-then sentences, both the if clause and the then clause are treated as one node in ETAT.

At this time, the segmenting procedure is done by hand. The nodes are grouped into blocks, with each block being formed by a maximum of 14 nodes. Paragraphs are normally approximately five sentences in length (MacNeally \& Hedges, 1996), so a 14-node block is approximately two to three paragraphs of text.

Node classification. A category is assigned to each node on the basis of its conceptual content. ETAT classifies the nodes into one of three classes: state (S), event $(\mathrm{E})$, and goal $(\mathrm{G})$. The category for style, as found in the CGS representation, was eliminated from ETAT given that style refers to modifiers of events or states that are not independent nodes in ETAT. The use of fewer categories, of course, simplifies the analysis.

1. State (S): A state is an ongoing state in the physical, social, or mental world. All sorts of definitions are states.
The heart is the hardest-working organ in the body. Coronary thrombosis is a clot that forms in a coronary artery.

Statistical regularities, conditional statements, comparative statements, and possible facts are also states. The statement nodes below are examples of each of these.

Most babies have perfect hearts.

When a baby's heart is badly formed, it cannot work efficiently.

More people are killed every year in the U.S. by heart disease than by any other disease.

We could propose models describing what might be happening inside a soft drink machine from the moment we put a coin in the slot to the moment the soda can comes out.

Statements referring to a person's mental states, emotional states, beliefs, attitudes, and sentiments are also classified as states.

Rutherford was aware of the penetrability of matter.

According to Thomson, space that might exist between spherical atoms in contact with one another was not enough to explain the great penetrability of matter.

Lenin's main preoccupation was the war against Germany.

States include static facts that describe a situation in a social environment.

During the 19th century Russia was kept on the sidelines of the revolutions which had transformed socially the rest of Europe.

The nobility and the clergy were still the dominant social groups.

2. Event (E). Statements about changes of physical or social states are categorized as events. These changes do not have to be brought about intentionally by an agent. The changes can occur not only in the physical and social worlds, but also cognitively (attitudes, beliefs, sentiments, and emotions). Obviously, some of these subclasses can occur only in animated beings, especially human beings. The following nodes are examples of events:

Between 1881 and 1914 economic growth took place in Russia thanks to foreign loans.

By the fall of 1964, pressure to strike directly at North Vietnam began to build.

Serious differences among American officials arose over the aerial extension of the war into North Vietnam.

The American colonists got very upset about taxes to support the French and Indian War.

3. Goal (G). These are statements about actions that are initiated intentionally (successful or not) by a human agent with the purpose of attaining a particular state or event. Desires are goals, even though they may not be realized as a concrete action; goals imply an intentional 
mental activity that may or may not be achieved by performing actions. The examples below are goals.

Political power was controlled by the Czars who reacted with a firm hand against any intent at reform.

The revolutionaries tried to eliminate the Czarist regime.

Most civilian members of the Johnson Administration favored the strategy of graduated response in the Vietnam War.

The military leaders emphasized destruction of the enemy's capability to support the war rather than his will.

The British started passing laws to tax the American colonies.

Node relationships. ETAT recognizes six possible directed conceptual relationships between nodes: initiate, outcome, reason, cause, description, and example of. The first four categories were taken directly from Graesser et al. (2001). The description relationship is similar to the relationships description-attribution and descriptionevidence in Meyer (1985). It also includes the arc category property, formulated by Graesser and Goodman (1985a). The example relationship is similar to the description-specific relationship in Meyer (1985). It includes the relationships similar to in Graesser et al. (2001) and example of in Bovair and Kieras (1985). We decided to include this relationship in ETAT because examples, analogies, and metaphors are frequently used in instructional texts. Each of these relationships has a composition rule that specifies the node categories that can be linked by a particular type of relation.

1. Initiate. An event or state initiates a goal. These events or states are temporal antecedents, and they specify conditions, circumstances, or situations to elicit a goal. Composition rule: $<\{\mathrm{S} \mid \mathrm{E}\}>$ - Initiate $\mathrm{I} \rightarrow<\mathrm{G}>$

Example: $<$ During the 19th century Russia was kept on the sidelines of the revolutions which had transformed socially the rest of Europe $>$ - Initiate $\rightarrow$ $<$ The minority proletariat pushed for revolution>

2. Outcome. A goal results in an event or a state that specifies whether or not the goal is achieved. The direction of the arc is the opposite of the relationship initiate.

Composition rule: $\langle\mathrm{G}\rangle-$ Outcome $\mathrm{O} \rightarrow\langle\{\mathrm{S} \mid \mathrm{E}\}\rangle$

Example: $<$ The Bolsheviks, who controlled the Soviet Congress and who were led by Lenin, forced Kerenski and his followers to flee $>-$ Outcome $\rightarrow<$ The Communist Party became the ruling force $>$

3. Reason. It is appropriate when a subordinate goal-1 is achieved in time prior to its superordinate goal-2. Thus, goal-1 is achieved in order to achieve goal-2. The connective in order to reveals the direction of the relationship.

Composition rule: $<\mathrm{G} 1>-$ Reason $\mathrm{R} \rightarrow<\mathrm{G} 2>$

Example: $<$ The revolutionariesmade Czar Nicolas II follow more politically liberal lines via the formation of a consultativeassembly called Duma $>$ - Reason $\rightarrow$ $<$ The revolutionaries tried to eliminate the czarist regime>
4. Cause. The cause relation has two subtypes: direct cause and enables. In the case of a direct cause, one state/event is both a necessary and sufficient condition for another state/event. In the case of enables, one state/event is necessary, but not sufficient, for another state/event.

Composition rule: $\langle\{\mathrm{S} \mid \mathrm{E}\}>-$ Cause $\mathrm{C} \rightarrow\langle\{\mathrm{S} \mid \mathrm{E}\}>$ Example: <Between 1881 and 1914 economic growth took place in Russia thanks to foreign loans> Cause $\rightarrow<$ The population grew notably $>$

5. Description. One node describes another when the first node describes one or more arguments belonging to the second node. An argument is a concept expressed in a sentence. The description relationship exists when one of the following semantic relationships is expressed: (1) attribute, property, characteristic, feature; (2) is-a-part-of, is-a-component-of; (3) label, name-of.

Composition rule: <Any node $>-$ Description $\mathrm{D} \rightarrow$ $<$ Argument of any node $>$

Example: $<$ We rely on the heart to supply blood regularly to the body every moment of every day> - Description $\rightarrow<$ The heart is the hardest working organ in the body>

6. Example. One node is an example of another node when the first (1) specifies a more general or abstract idea formulated in the second, (2) is an analogy or metaphor of the second, (3) is-a-part-of, is a member of. The example relation can be established only between nodes classified in a like manner (i.e., $\mathrm{S}-\mathrm{S}$, $\mathrm{E}-\mathrm{E}$, and $\mathrm{G}-\mathrm{G})$.

Composition rule: $\left\langle\left\{\mathrm{S}_{\mathrm{i}}\left|\mathrm{E}_{\mathrm{i}}\right| \mathrm{G}_{\mathrm{i}}\right\}>-\right.$ Example $\mathrm{Ex} \rightarrow$ $<\left\{S_{j}\left|E_{j}\right| G_{j}\right\}>$

Example: <If we were to imagine the nucleus blown up to the size of a volley ball, the atom would be like an enormous bubble 12.5 miles in diameter $>-E x$ ample $\rightarrow<$ According to Rutherford's calculation, the diameter of the tiny nucleus was between 10,000 and 100,000 times smaller than the diameter of the atom $>$

ETAT distinguishes between explicit and implicit relationships between nodes. A relationship is explicit when a linguistic expression exists in the text that clearly indicates the relationship between nodes. For example, in the sentence The United States never did put Project $X$-Ray to use since by 1945 the atomic bomb had been perfected, the adverb since makes the causal relationship between the two nodes explicit. The relationship between nodes is implicit when the reader establishes the relationship via an inference. The first four relationships explained above are implicit; that is, only a reader with sufficient background knowledge can make the necessary inferences to decide that a relationship exists between two ideas in the text. An expository text in which there are large quantities of implicit relationships between ideas might present serious comprehension difficulties for many readers (Britton, van Dusen, Glynn, \& Hemphill, 1990).

ETAT establishes the relationship between nodes by phases. In Phase 1, ETAT examines the relationships be- 
tween all of the nodes within each block. ETAT then automatically selects those nodes with the greatest number of relationships within each block. These highly related nodes are regrouped into new blocks, which provide the input to Phase 2. Since new blocks in Phase 2 are composed of nodes that were located in different blocks in Phase 1, they will have to be interrelated in this phase. After examining the internodal relationship, ETAT once again selects those nodes with the greatest number of relationships within each block and then regroups them in new blocks, creating Phase 3. In this way, each new phase obtains new blocks formed by the nodes that are best related to the previous phase. The process continues until the analyst reaches a phase in which there is one final block. It is therefore possible to analyze a lengthy text without having to interrelate all of the nodes of the original text, an analytically time-consuming task. One consequence of this method is that the less important nodes get lost along the way and fail to make it into the final analysis.

In addition to the six previously described relationships, (i.e., cause, describe, initiate, etc.), ETAT permits the automatic establishment of another nondirectional relationship between pairs of nodes: keyword overlap $(\mathrm{K})$. Overlap is established between nodes that share terms with the same etymological root. For example, in a text about the Russian revolutions, if two nodes share terms with the etymological root Rus- (e.g., Russia, Russian), ETAT automatically establishes the overlap relationship between them. The analyst decides which keywords of the text should be considered to establish this relationship-normally, those that can be found in the title or headings within the text, and generally no more than two to three words.

Overlap between arguments in a text significantly predicts the reader's recall (Miller \& Kintsch, 1980), is a foundation for text coherence (Britton \& Gülgöz, 1991; Britton et al., 1990), and is one definition of text structure (Ferstl \& Kintsch, 1998). Argument overlap is a popular component in comprehension models, because it is a straightforward mechanism that makes connections between sentences (Goldman, Varma, \& Coté, 1996; Kintsch, 1998; Mannes \& George, 1996; Turner, Britton, Andraessen, \& McCutchen, 1996). Keyword overlap is an option offered by ETAT.

Keyword overlap is useful when an author places an important node $n_{\mathrm{i}}$ in a block $B_{\mathrm{i}}$ formed by nodes that have little apparent interrelationship. In this case, if the keyword overlap option is not used, $n_{\mathrm{i}}$ will not be selected in Phase 2, since it is not related to the rest of the nodes in block $B_{i}$. Thus, it would be impossible to relate $n_{\mathrm{i}}$ with the other important nodes in Phase 2 and other posterior phases. However, if keyword overlap is used, $n_{\mathrm{i}}$ will probably be selected for Phase 2 , because it will most surely share one or more keywords with other nodes in block $B_{\mathrm{i}}$, being an important node in the text. Consequently $n_{\mathrm{i}}$ will not be lost, and it will be possible to examine its relationship with other important nodes of the text in Phase 2 and posterior phases.

\section{Technical Description of ETAT}

Hardware and software requirements. The program was developed in Java (Naughton \& Schildt, 1997) with a compiler Jbuilder. It can be used on a PC, a MAC, and any other system in which a virtual Java engine has been implemented. The program functions correctly with a 486 processor, a minimum of $16 \mathrm{Mb}$ of RAM memory, and Java support. ETAT occupies $30 \mathrm{Mb}$ of hard disk space.

Interface features. ETAT has the normal features of a Windows environment, such as multiple menus and menu options, selection of options with a mouse and point-and-click facility, and a keyboard for alphanumeric input. The interface has been designed to have rapid access to all information that is produced in the text analysis process. Along with the menu bar, the screen is divided into two parts. In the upper part there is a record of work, whereas in the lower part there is a record of information (see Figure 1).

In the record of work, one can see the results of each of the three analytical steps. On the left is shown the Tree of Phases. Clicking on the Text option in the tree, one can access the nodes of the whole text, whereas clicking on one of the blocks provides access to the nodes of the block. On the right of the record of work, the results of each of the analytical steps are shown. Likewise, clicking on the Text button brings up the result of the segmentation step, clicking on Category obtains the results of the second step, and clicking on Relations shows the third step results.

The record of information produces complementary information. Clicking on Text brings up the complete original text that is undergoing analysis. Clicking on nodes permits us to see the most important nodes selected by ETAT after passing through Phase 1 . The Nodes to Relate function reads the content of each pair of interrelated nodes, indicating with an arrow the direction of the relationship.

\section{Working with ETAT}

ETAT works from documents that contain previously segmented texts. In such a document, one node is separated from another by a single space. The nodes are grouped in blocks, with a maximum number of 14 nodes in each block. The blocks are separated from one another by a double space. Once prepared this way and saved as ASCII, a text can be imported from ETAT via the Import option of the File menu. Using this option on a prepared text, ETAT creates Phase 1 from the Tree of Phases, in which the nodes appear as numbered and grouped in blocks (see Figure 1). The option then proceeds to categorize and interrelate the nodes of each block.

Node classification. After the user selects a block from the Tree of Phases and hits Category, ETAT produces a window to categorize the nodes (see Figure 2). To categorize a node, the user clicks on the node in question, marks one of the three options (i.e., G, S, or E, which correspond to goal, state, or event), and then clicks Categorize. Once the node has been categorized, the $\mathrm{G}, \mathrm{S}$, or $\mathrm{E}$ will appear along with the number that represents that node (see Figure 2). 


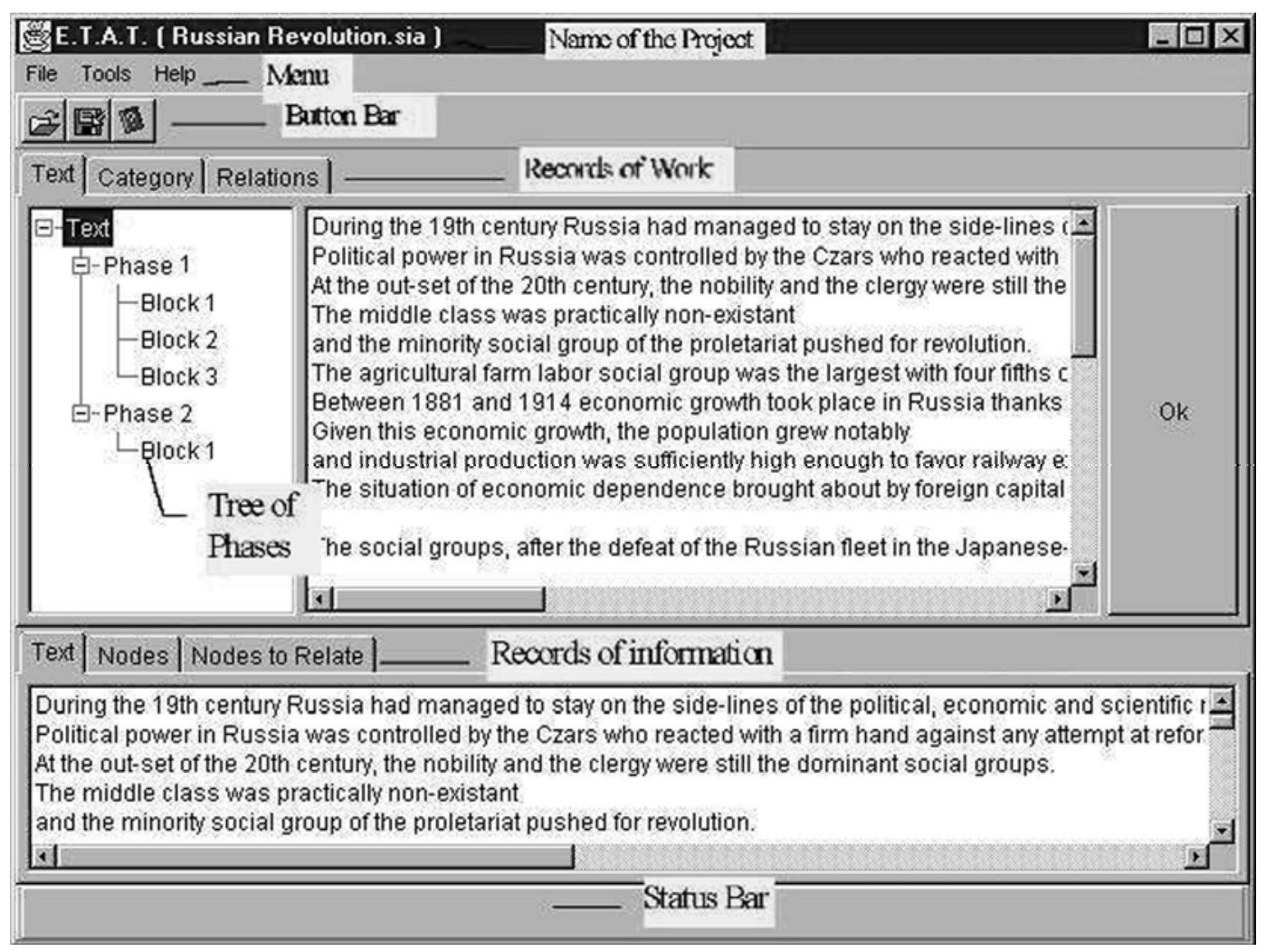

Figure 1. First ETAT screen showing main interfaces.

To aid in the categorization process, the user may click on any of the three options (G, S, or E), and a definition of each will appear in the lower left-hand side. When all the nodes of a block have been categorized, the user clicks OK and repeats the procedure with the rest of the blocks of Phase 1.

Node interrelationships. To interrelate the nodes of a block, the user selects the block in the Tree of Phases and then hits Relations. ETAT will show a $N \times N$ matrix that is formed by the $N$ nodes of the block being ana- lyzed; the numbers designate the nodes (see Figure 3). The user proceeds with testing whether a relationship exists between each pair of nodes in the block, thereby deciding, if affirmative, the kind of relationship (e.g., initiate, reason) and its direction.

As an example, to test whether there is a relationship between Nodes 2 and 1, the user would click over cell $[2,1]$. In this case only the outcome and description relationships would be available, because these are the only two relationships that legally can connect a goal node

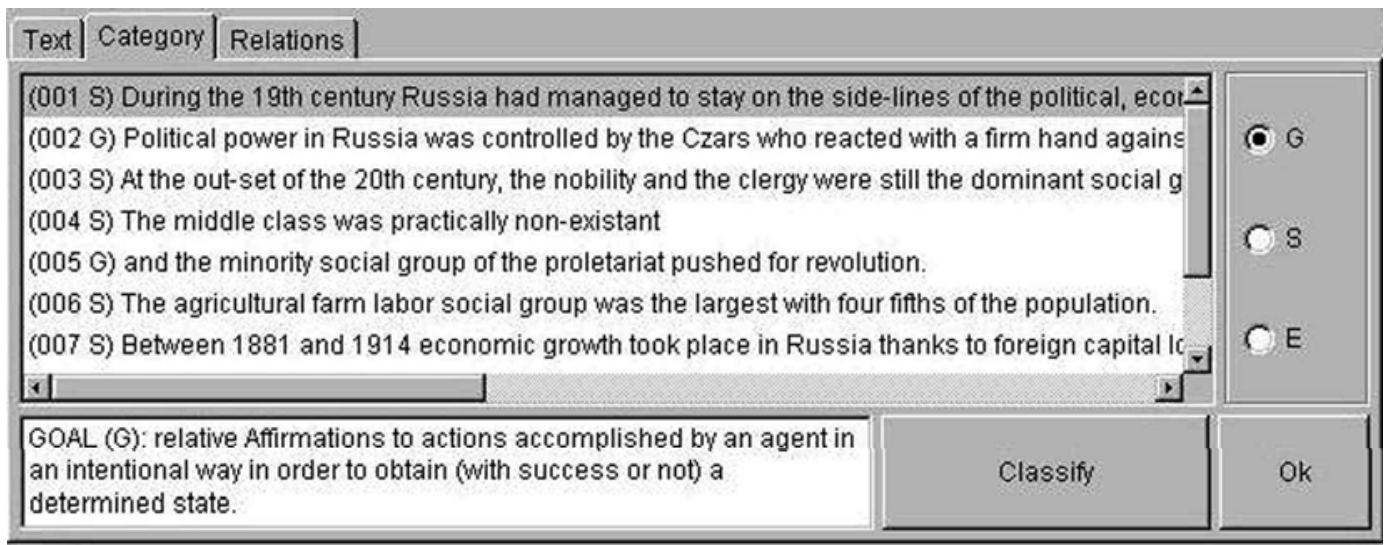

Figure 2. ETAT screen for the procedure to categorize the nodes of a block. 


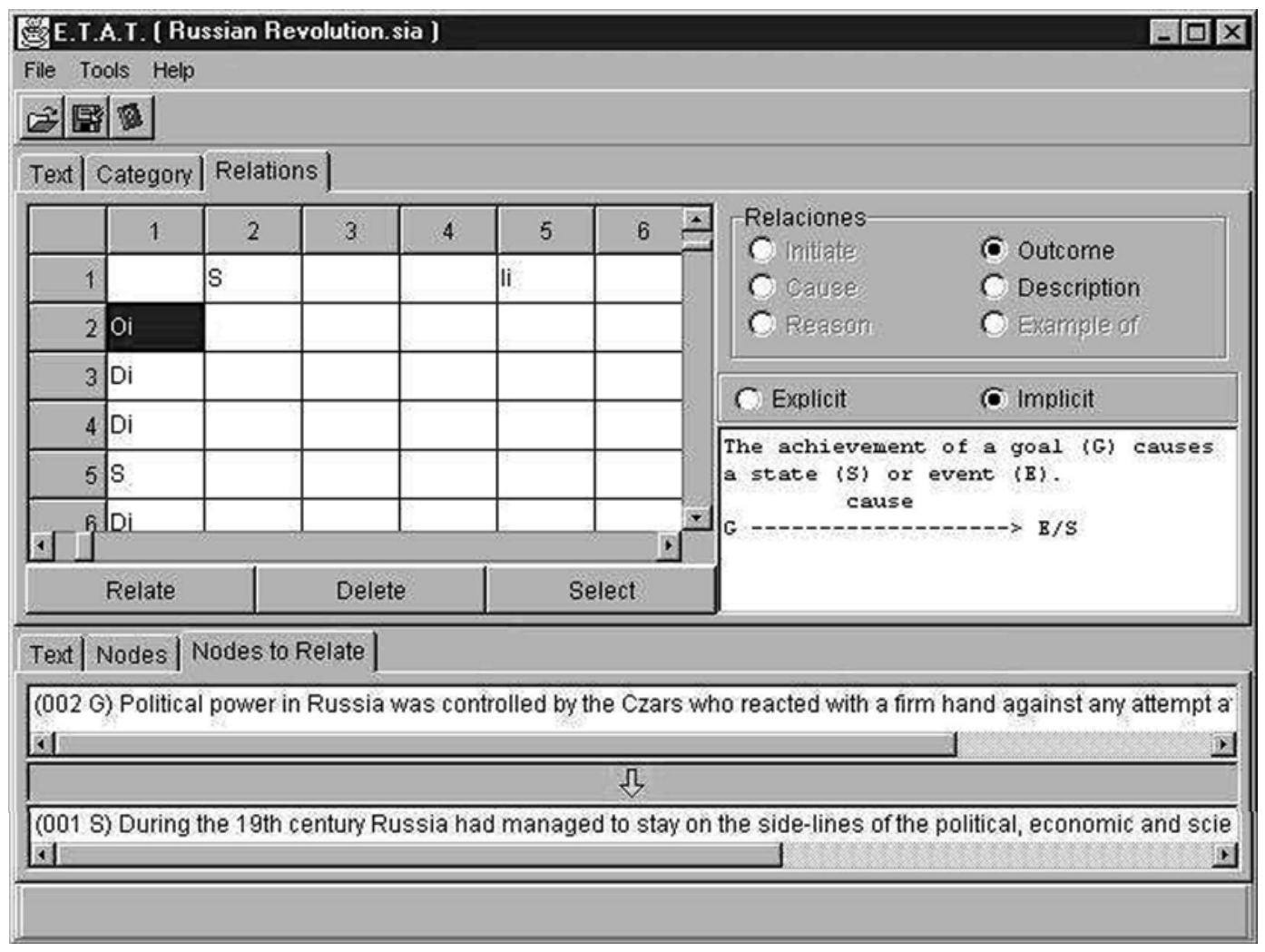

Figure 3. ETAT screen for the procedure to interrelate the nodes of a block.

(Goal [2]) and a state (State [1]). In this case, the outcome relationship is correct and is selected by clicking the Implicit option, given that it is implicit (see Figure 3). The user then clicks on Relate to register the relationship. Hitting Delete can erase any relationship. Please note that all these conceptual relationships have a single direction. For example, the relationship between Nodes 1 and 2 can be either $(1,2)$ or $(2,1)$, but not both, because either Node 1 (state) initiates Node 2 (goal), or Node 2 (G) produces an outcome of Node $1(\mathrm{~S})$.

The analyst can read the contents of the nodes by hitting Nodes-to-Relate in the lower part of the screen (i.e., records of information). One can also see the definition and composition rule of the chosen relationship (see Figure 3). The described process is followed for all pairs of nodes of a block and with all of the blocks in Phase 1.

After interrelating the nodes in all the blocks, the analyst is able to automatically establish the keyword overlap relationship. To do so, the user selects the Keyword Overlap option from the Tool menu, declares the etymological root of the two to three most important words in the text, and clicks Accept. ETAT automatically establishes the keyword overlap relationship between nodes that share the words with some of the introduced roots and puts a $\mathrm{K}$ in the corresponding cells of all of the Phase 1 blocks. Unlike the previous relationships, keyword overlap is bidirectional, because the interrelated nodes share a com- mon keyword. Therefore, if two nodes $a$ and $b$ share a keyword, ETAT will mark the cells $(a, b)$ and $(b, a)$.

For example, in the analyzed text represented in Figure 3, the etymological roots Rus for Russia and Revol for Revolution were introduced because the title of the text was The Russian Revolutions. Thus, after hitting the Keyword Overlap option from the Tool menu, ETAT established the keyword overlap relationship (K) between Nodes $(1,2)$ (i.e., overlapping Russia) and $(5,1)$ (i.e., overlapping revolution; see Figure 3). Despite the fact that relationship $\mathrm{K}$ is bidirectional, ETAT has not marked it in cells $(2,1)$ and $(1,5)$, because both had been previously marked with other conceptual relationships, $\mathrm{O}_{\mathrm{i}}$ and $\mathrm{I}_{\mathrm{i}}$, respectively. Conceptual relationships take preference over the keyword overlap relationship.

After testing the interrelationship between the nodes of all the blocks in Phase 1, the analyst proceeds to select the most important nodes, in order to analyze their interrelationships in Phase 2. To select these nodes, the user hits the Select button (see Figure 3), and ETAT automatically applies the selection algorithm. According to the result, in each block of Phase 1, ETAT will select the node with the greatest number of relationships. If the selected node (e.g., $\mathrm{X}$ ) is related to another node with an arc going out from it (e.g., X Cause Y), the new node (i.e., $Y$ ) is also selected. If the selected nodes (i.e., $\mathrm{X}$ and Y) do not exceed $30 \%$ of the nodes in the block, ETAT 
will repeat the operation with the next highly related nodes. ETAT will cease to select nodes when a minimum of $30 \%$ of the nodes in the block have been selected.

If the result of the selection process is a number of nodes equal to or less than 14, ETAT will regroup them into a single block, as is illustrated in Figure 1. Otherwise, ETAT will create new blocks, none of which will have more than 14 nodes. In general, from one phase to another, the number of blocks is reduced to between a half and a third of the original phase.

In Phase 2, the analyst subsequently tests the interrelationships between the pairs of nodes of each new block whose interrelationship was not previously examined in Phase 1. When this phase terminates, the analyst once again selects the most important nodes, producing Phase 3 . Then the analyst would again interrelate the nodes from each block that had not been previously interrelated. The process of analysis stops when the end of the text is reached.

\section{Results of the Analysis}

ETAT produces three results that are accessible from the Tools menu: Graphs, Isolated-nodes, and Statistics. These results permit the analyst to examine the internal coherence of the text.

Graphs. ETAT produces a graph with interrelationships between nodes (see Figure 4). The position of the different nodes in the graph can be corrected manually with the mouse, if so desired, to reorganize the graph. Each node is represented by its order number and is ac- companied by the letter that symbolizes the category to which each node belongs. The nodes are united by solid arrows if the relationship is explicit and by broken arrows if the relationship is implicit.

The graph can be seen in its entirety with or without the interrelationship symbols. If desired, the graph can be modified to view only a particular relationship or a combination of relationships. It is also possible to generate a graph with only the nodes of a particular block or of a particular phase or with all of the nodes of the text. By double-clicking on the part represented by a node, all of the information about that node can be accessed (i.e., content, relationships received, relationships emitted, and the total number of relationships shared with other nodes within the particular block or within the entire text).

The graph provides a wide range of information. It permits us to see: (1) the nodes with the greatest number of interrelationships, (2) the types of relationships that are established with the remaining adjacent nodes, and (3) whether the relationships are explicit or implicit. The graph also permits us to observe chains of relationships established between nodes (e.g., initiate-reason-outcome, cause-effect).

Isolated nodes. With this option, ETAT provides information about nodes or groups of nodes that are not interrelated to the rest of the nodes. A coherent text should not contain isolated nodes (Britton et al., 1990). If isolated nodes are present, the analyst should examine the functions or positions of these nodes in the text.

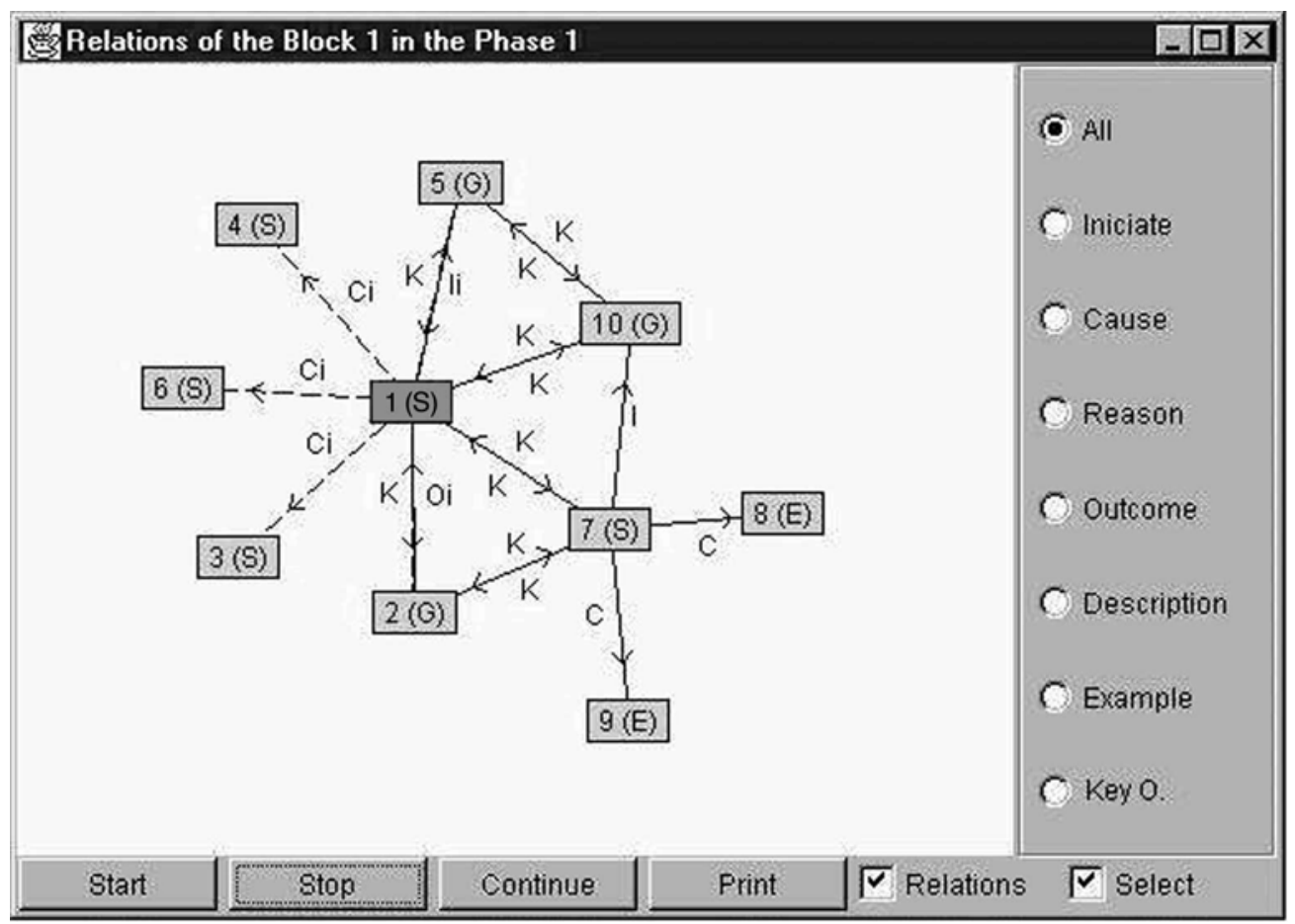

Figure 4. Graph produced by ETAT. 
Table 1

Indices of Reliability on the Analyses of Two Texts Carried Out by Five Undergraduate Students

\begin{tabular}{cccc}
\hline Text & Simple Concordance & Jaccard & $\begin{array}{c}\text { Relationship } \\
(\%)\end{array}$ \\
\hline 1 & .971 & .724 & 73 \\
2 & .942 & .557 & 100 \\
\hline
\end{tabular}

Statistics. This option provides a series of statistics with respect to the following interrelationships found in the analyzed text: (1) number of interrelationships between nodes (e.g., initiate, outcome, or total), (2) number of explicit or implicit relationships, (3) means and standard deviations of the number of interrelationships per node, and (4) proportion of explicit interrelationships.

\section{Time Demands and Intersubjective Reliability Between Analysts}

In order to test time demands and intersubjective reliability between analysts, we carried out two studies. In the first, 5 undergraduate students were taught to analyze expository texts with ETAT. The students received $20 \mathrm{~h}$ of training. They first received extensive practice in segmentation, classification, and establishing relationships between nodes by hand, in order to understand the analysis procedure. Once they had reached a high level of learning, they were trained to carry out the analysis with ETAT. It should be noted that most of the training time was devoted to making the students understand the rules for segmenting, classifying, and relating nodes, but not to instruction on using ETAT. At the end of the training, the students analyzed independently two short sixthgrade expository texts with ETAT. In accordance with ETAT's criteria for node segmentation, one text contained 214 words and 13 nodes, whereas the other consisted of 154 words and 10 nodes. First, the students segmented the texts into nodes. The majority of the students segmented the text correctly, reaching agreement on $100 \%$ after resolving a few discrepancies. Next, they classified the nodes of both texts. The average percentage of agreement was $94.6 \%$. After the discussion period, they reached $100 \%$ agreement. Finally, the students went on to relate the nodes.

In order to evaluate the reliability among the students in the relation phase, we used two indices: an index of simple concordance and the Jaccard index. In the index of simple concordance, the concordance between pairs of subjects is measured, concordance being considered both agreement when two nodes $a$ and $b$ are related and agreement when no relation exists between them. The Jaccard index is more demanding and does not count as concordance the case in which the 2 subjects agree that there is no relationship between the nodes. That is, only decisions regarding the existence of a relationship between two nodes are counted. In both indices, we only consider whether students marked some relationship between pairs of nodes, regardless of the type of relation- ship they marked (e.g., cause or description). In order also to evaluate the degree of agreement on the type of relationship, we determined the percentage of agreement on the type of relationship over the total number of agreements. That is, if 10 decisions were made by each analyst and there was agreement on the type of relationship (e.g., cause or description) on only 8 of the decisions, the percentage of agreement would be $80 \%$.

As is shown in Table 1, there is greater agreement in Text 1 than in Text 2, both on the simple concordance index and the Jaccard index. This can be explained by the fact that Text 1 has a simpler content structure than does Text 2. This latter text has more cross-connections between distant nodes. However, once it had been decided that there was a relationship between two nodes, in Text 2 there was complete agreement on the type of relationship that had to be established (100\%), this agreement being less in the case of Text $1(73 \%)$.

The average time dedicated to the analysis of the two texts by the students was 42 min, not counting the initial reading and rereading and the discussion for reviewing the results and reaching agreements. Analyzing the texts and obtaining the graphs and all the statistics provided with ETAT by hand would take approximately $6 \mathrm{~h}$.

To evaluate the effect of the complexity of the content structure on the agreement between analysts, we carried out a second study. Two of the authors of this study analyzed independently four texts taken from Goldman et al. (1996), two of which ("Distance" and "Nationalism") had simple content structures, whereas the other two ("Fat" and "Sugar") had more complex content structures. We have left out more detailed explanations of the content structures of these texts here because they can be found in the Uses of ETAT section. The four texts were of similar lengths, oscillating between 321 words in the passage on "Nationalism" and 344 in the "Distance" text. However, the number of nodes was greater in the complex texts (i.e., 28 and 31 nodes in "Fat" and "Sugar," respectively) than in the simple ones (i.e., 22 and 21 nodes in "Distance" and "Nationalism," respectively).

The average analysis time was less in the simple texts (i.e., 25 and 37 min for the "Distance" and "Nationalism" texts, respectively) than in the complex ones (i.e., 65 and 50 min for the "Fat" and "Sugar" texts, respectively). The coincidence on the classification of nodes was

Table 2

Indices of Interjudge Reliability on the Analysis of Four Texts, Two of Them With a Simple Structure and Two With a Complex Structure

\begin{tabular}{lccc}
\hline \multicolumn{1}{c}{ Text } & Simple Concordance & Jaccard & $\begin{array}{c}\text { Relationship } \\
(\%)\end{array}$ \\
\hline Simple structure & & & \\
$\quad$ Distance & .98 & .88 & 75 \\
$\quad$ Nationalism & .98 & .80 & 93 \\
Complex structure & & & \\
$\quad$ Sugar & .98 & .79 & 95 \\
$\quad$ Fat & .98 & .78 & 81 \\
\hline
\end{tabular}


$100 \%$ for "Distance" and "Sugar," $96 \%$ for "Fat," and 90\% for "Nationalism." The few discrepancies were completely resolved, reaching a final agreement of $100 \%$.

To evaluate the reliability among analysts in the node interrelationship phase, we obtained the same indices as those in the previous study (see Table 2). As can be seen, in this case the indices are higher than in the first study, which indicates that an increase in experience in using ETAT increases the reliability of its use. Likewise, in general, greater agreement is observed on the texts with a simple structure than on those with a complex structure. The difficulty of the latter lies in the numerous connections between distant nodes, which are more difficult to perceive. Comprehension implies subjective constructive processes that may cause the mental representation formed by two different readers not to be identical. Finally, we would like to point out that the discrepancies in the type of relationship in two of the texts (i.e., "Distance" and "Fat") is due to different interpretations of diverse relationships between nodes. In the first case, some relationships were interpreted as description by one analyst and as example by another. In the text on "Fat," something similar occurred with the description and cause relationships. It must be pointed out that in all of the cases, $100 \%$ agreement was reached after a brief period of discussion.

\section{Uses of ETAT}

ETAT can be used to analyze the coherence level of texts. To test its usefulness, we have analyzed versions of texts with high and low coherence published in five studies on text revision (Beck et al., 1991; Britton \& Gülgöz, 1991; Linderholm et al., 2001; McNamara et al., 1996, Experiment 2; Vidal-Abarca et al., 2000). We have compared the mean and standard deviations of interrelationships per node and the proportion of explicit relationships of the high and low coherence versions (i.e., original and revised versions, respectively). The result of the analysis is shown in Table 3. In the two studies in which various coherent versions were used instead of just one (i.e., McNamara et al., 1996, and Vidal-Abarca et al., 2000), we have used the most coherent versions to compare with the original passage.

In agreement with the results of the analysis, the revisions by Britton and Gülgöz (1991) and by Beck et al. (1991) consisted of making the relationships between the ideas in the text more explicit, the proportion of explicit relationships over the total number of relationships increasing from $36 \%$ to $81 \%$ in the first case and from $15 \%$ to $71 \%$ in the second. This change coincides exactly with what these authors intended to do in the revised versions. Thus, Britton and Gülgöz stated that they made the revised version more coherent by inserting the missing inferences readers should make to understand the text (p. 330). In the same way, Beck et al. stated that "the general operations used in making revisions were ... making connections explicit" (p. 256).

The procedures followed for increasing the coherence in the three remaining studies were quite different. In all of them, the main change consisted of introducing information to benefit the connection between the main ideas of the original passage. ETAT detected this change by means of an increase in the mean and standard deviation of interrelationships per node. The mean increases owing to the fact that the added ideas increase the relationships between the nodes of the text. The standard deviation increases because this increment in relationships is not uniform but, rather, occurs mainly between the most important nodes. It must be noted, furthermore, that in all of these studies, the increase in the percentage of explicit relationships over the total number of relationships is scant, much less than that of the two previously mentioned studies.

Again, it is important to point out that the change detected by ETAT coincides with the changes introduced in the coherent versions by the different researchers. The changes introduced by McNamara et al. (1996) were directed toward increasing the connection between textual ideas. A large number of these connections were established between the most important ideas by the introduction of macropropositions. The most coherent version of the Vidal-Abarca et al. (2000) study had a component of argument overlap, which was detected by ETAT by means of the increase in the percentage of explicit relations in the revised version (from 29\% to 37\%). There was another, more important, information introduction component to facilitate the connection between the most important nodes of the text, which was detected by ETAT by means of the increase in the mean and standard deviation of relations per node. Finally, Linderholm et al. (2001) made goals of main characters explicit, restored the temporal order of events, and repaired coherence breaks by inserting events to make causes of events more clear or by shortening the distance between causes and conse-

Table 3

Comparisons of Original and Revised Versions of Text Revision Studies Using ETAT's Indices

\begin{tabular}{lcccccccc}
\hline & \multicolumn{3}{c}{ Original Version } & & \multicolumn{3}{c}{ Revised Version } \\
\cline { 2 - 3 } \multicolumn{1}{c}{ Study } & $M$ & $S D$ & Exp & & $M$ & $S D$ & $\%$ Exp \\
\hline Britton and Gülgöz, 1991 & 1.35 & 2.47 & 36 & & 1.32 & 2.77 & 81 \\
Beck, McKeown, Sinatra, and Loxterman, 1991 & 1.30 & 2.14 & 15 & & 1.10 & 1.62 & 71 \\
McNamara, Kintsch, Songer, and Kintsch, 1996 & 0.89 & 1.14 & 36 & & 1.07 & 1.77 & 35 \\
Vidal-Abarca, Martínez, and Gilabert, 2000 & 1.17 & 2.10 & 29 & & 1.68 & 2.58 & 37 \\
Linderholm et al., 2001 & 0.80 & 1.05 & 27 & & 1.48 & 2.56 & 32 \\
\hline
\end{tabular}

Note-ETAT indices: $M$, mean of interrelationships per node; $S D$, standard deviation of interrelationships per node; \% Exp, proportion of explicit relationships. 
quences. These changes involve increasing the number of relations between the most important nodes of the text, which is what ETAT detects by means of the increase in mean and standard deviation of interrelationships per node.

In short, ETAT captures the level of coherence of texts by means of three indices-that is, mean and standard deviation of interrelationships per node and proportion of explicit interrelationships between nodes. In addition, ETAT shows that there are at least two ways to improve text coherence. The first is by making node interrelationships more explicit, which increases the proportion of explicit interrelationships between nodes. The second is by inserting information to connect important nodes, which increases the mean and standard deviation of interrelationships per node.

A second use of ETAT is to identify points at which text coherence breaks occur in a text. On the basis of the graph representing the relationships between the nodes of a text, it is possible to see breaks in coherence and implicit connections between the nodes of a text. This information can aid in making decisions about what information should be added to increase the coherence of the text. This was the procedure followed by VidalAbarca, Sanjosé, et al. (2001) to improve the textual coherence of an eighth-grade passage on the evolution of the species.
Figure 5 shows the graph of the original version of the text on evolution. Two groups of nodes appear that are disconnected from the rest-that is, Group $1-2-3$ and Group 4-5-6-7. Furthermore, there is only one connection between the block composed of Nodes $8-18$, where the Lamarck theory is explained, and the block composed of Nodes 19-30, where Darwin's theory is explained. Moreover, the connection is relatively superficial (i.e., both nodes mention the expression evolutionist theory). On the other hand, $74 \%$ of the connections are implicit. This occurs in all of the causal connections and in the majority of the initiate and outcome connections. Two especially difficult implicit connections are the causal relationships between Nodes 22 and 28 and between Nodes 22 and 29, given the distance between both pairs of nodes. These data should be taken into account to increase the coherence of the text. ETAT does not provide information on how to solve coherence problems, but rather on where it is probable that a reader who is not very knowledgeable about the topic would have difficulties in forming a coherent representation of the content of the text.

ETAT can also be used to evaluate the structural complexity of texts. To test this third utility, we analyzed four texts used by Goldman et al. (1996), two with simple content structure and two with complex structure. In agreement with Goldman et al., the two passages with

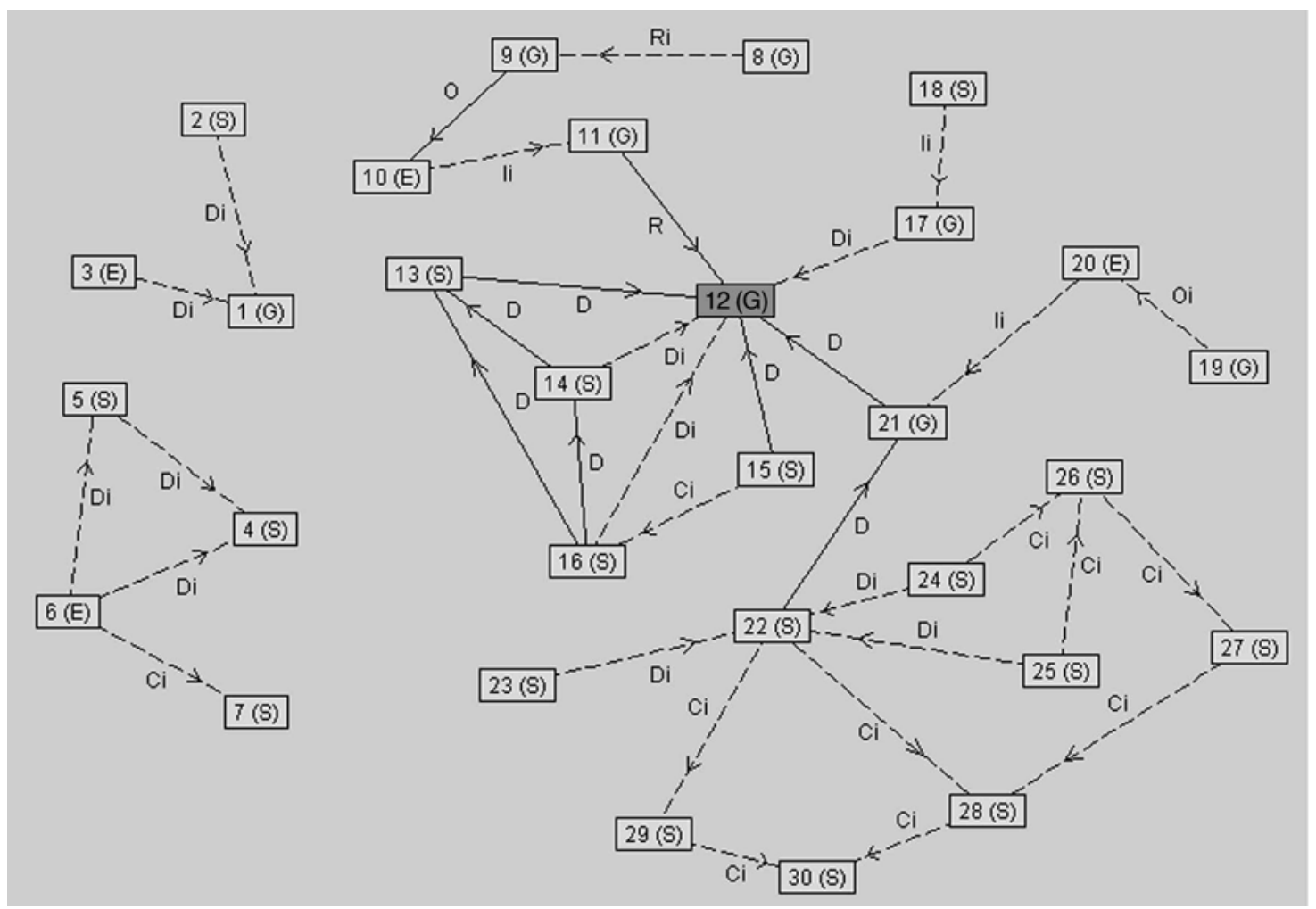

Figure 5. Graph of the original version of the text on evolution used by Vidal-Abarca, Sanjosé, Gilabert, and Abad (2001). 


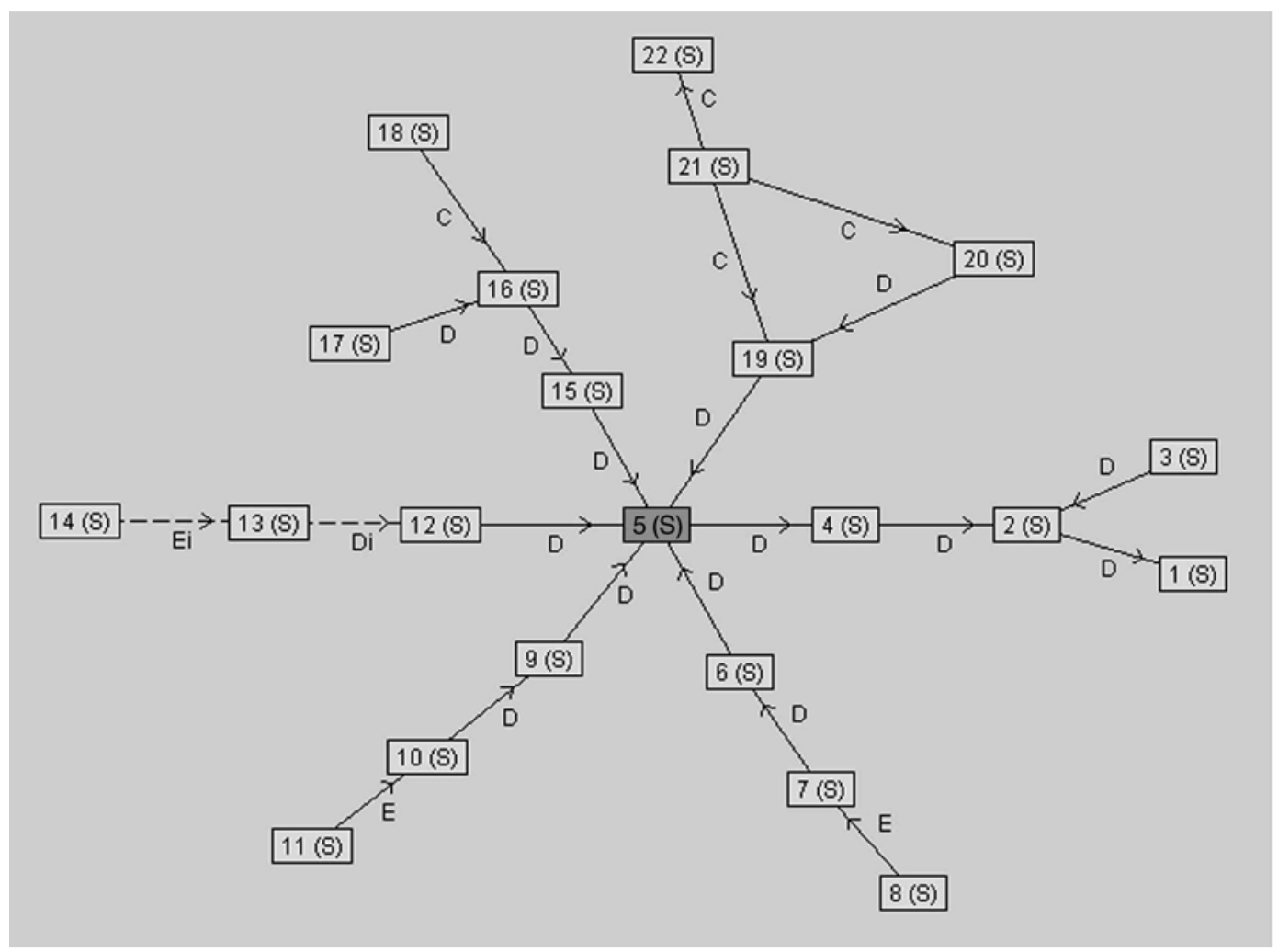

Figure 6. Graph of the text "Distance" created by ETAT.

simple structure (i.e., "Distance" and "Nationalism") contain a general topic and different subtopics, with distinct sentences constituting the information for each subtopic. In Figure 6, the graph of the "Distance" text elaborated with ETAT can be seen. There is a node with multiple connections (i.e., Node 5), in which it is stated that there are a number of factors that affect distance measurement. Five different factors are explained in the text, which can be clearly seen on the graph. The explanation is very simple for factors explained in the groups of Nodes 6-8, 9-11, and 12-14 but is a little more complex in groups 15-18 and 19-22. The text also contains an introduction to the topic in Nodes 1-4. There are no cross-connections among the different factors.

In agreement with Goldman et al. (1996), the two passages with complex structures (i.e., "Fat" and "Sugar"), while having a general topic (e.g., fat) and several subtopics (e.g., types of fat), also contain clusters of information (e.g., sources of fat and ways it is harmful), cross-connections between the clusters, and embedded enumerated structures. As can be seen in Figure 7, the graph of the "Fat" passage is far more complex than the "Distance" graph. ${ }^{1}$ There is an initial node (Node 1) that deals with the importance of fats, followed by diverse nodes that explain the reasons for this importance. Nodes 5-7 introduce information on fats and health, whereas Nodes 8-12 discuss the food sources of fats.
Node 13 is connected to Node 1 and describes the different kinds of fats. Nodes 14-18 deal with saturated fats, Nodes 19-21 talk about polysaturated fats, and Nodes 22-25 discuss the monosaturated fats. These three groups of nodes have multiple connections between them, because the text compares the different types of fats. There are also connections with the groups of Nodes 5-7 and 8-12, because they explain the food sources of fats and the ways they can be harmful to health.

These structural differences between the two textsthat is, "Distance" and "Fat"-are also reflected in the statistics provided by ETAT. As would be expected, the mean of the number of interrelationships per node is higher in the more complex text: 1.39 , as compared with 1.00 for "Fat" and "Distance," respectively. Likewise, the standard deviation of the number of interrelationships per node is higher in "Fat" (1.93) than in "Distance" (1.15), since the variability of the number of relationships per node is greater in the more complex text.

In summary, ETAT can be used to evaluate the structural complexity of expository texts. This structural complexity will be manifested in the graph mainly as multiple crossed connections between groups of nodes are observed, which will cause an increase in the average number of relationships per node. If the increase in relationships is unequal because some nodes are affected more than others, an increase in the standard deviation of 


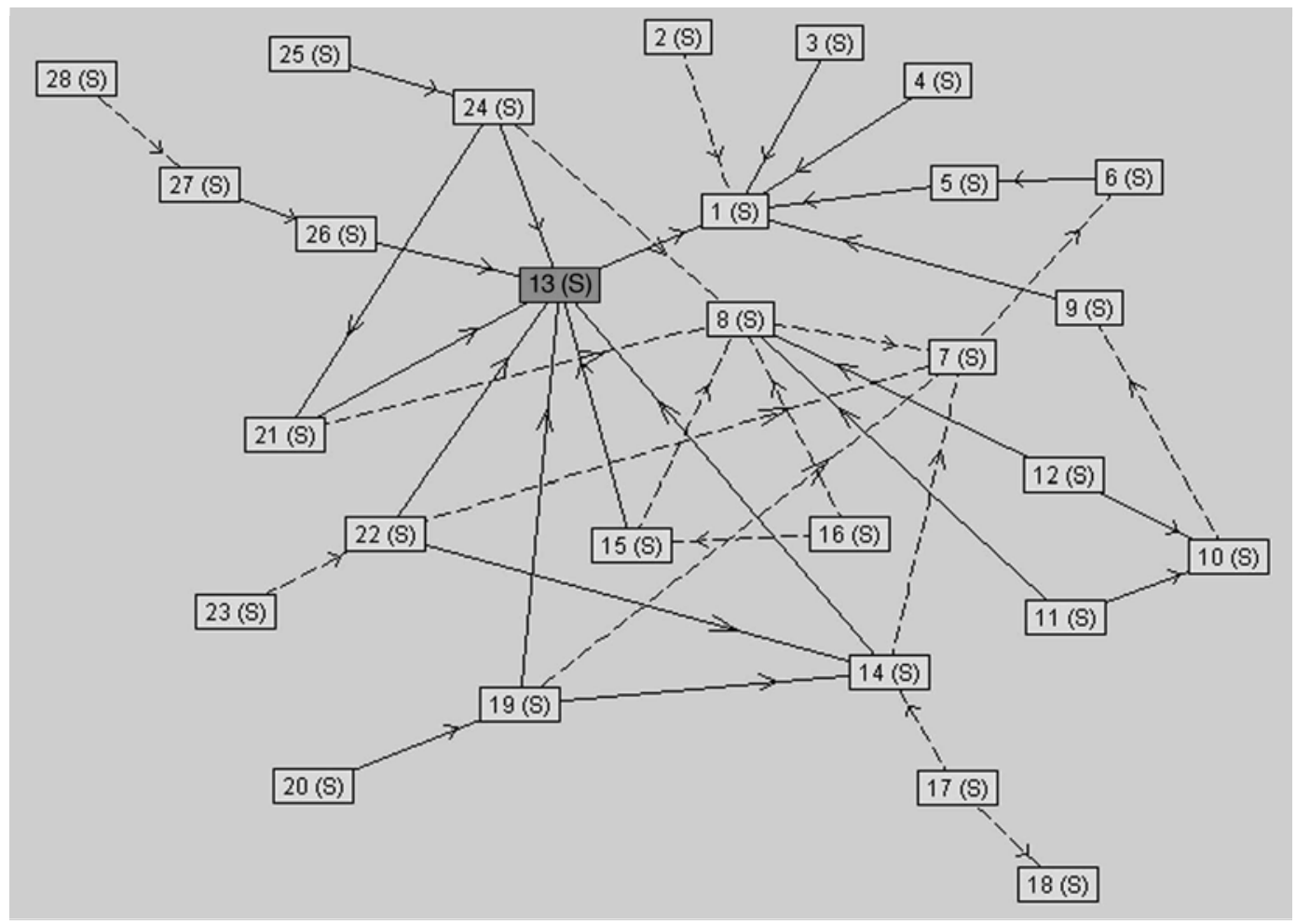

Figure 7. Graph of the text "Fat" created by ETAT.

the number of relationships per node will also be observed.

Finally, ETAT can also be useful for designing precise reading comprehension measurements. For example, ETAT can be used to check whether readers make certain inferences. Given that the ETAT graph represents implicit relationships between nodes, researchers can make up questions to test whether the readers perceive the relationships represented in the graph. If the ETAT graph represents the fact that two nodes, $\mathrm{X}$ and $\mathrm{Y}$, are connected by an implicit causal relationship, a specific question can be elaborated to test whether readers have perceived this relationship. In the case in which there were different versions of the same text and, in one of them, the relationships were expressed in a different way (e.g., the nodes were nearer to each other, or there was additional information to facilitate the inferential connection), ETAT would help the researcher to formulate precise predictions about the role of the textual changes in the inferential connection.

The latter use was investigated by Vidal-Abarca, Gilabert, and Abad (2001). We compared two of the versions of a text used by McNamara et al. (1996, Experiment 2) - that is, the versions with the lowest and the highest coherence-and a third passage of the same text created specifically for the study. This procedure allowed us to clarify the effects of diverse textual changes on comprehension, which would have been impossible with other, more general, measurement tools.

\section{EXTENSIONS OF ETAT}

One of ETAT's principal limitations at this time is the lack of automation within some analytical steps. In its current form, the analyst must make all of the decisions for each of the analytical steps along the way-that is, segmentation of text nodes, their categorization, and the establishment of the interrelationships between nodes. Future work will attempt to automate many of these steps.

A further challenge is the production of summaries. Taking advantage of ETAT's ability to select nodes with the greatest number of relationships - that is, the most important nodes-and the conceptual relationships among them, ETAT could generate an outline summary that could then be corrected by the analyst. For example, one could test whether the nodes with the greatest number of interrelationships contain the fundamental ideas of the text.

One last possible extension of ETAT is the automatic generation of questions by using the interrelationship links that form a continuous chain between nodes in the interrelationship. For example, if we see that one of the events is the cause of another, ETAT would automatically generate a question that taps causal antecedents or causal consequences. Given that the distance between both events is known, as well as whether the causal relationship that connects them is explicit or implicit within the text, it is possible to grade the questions according to 
their difficulty. This is especially useful when generating questions in school room situations in order to help the reader make inferences that he or she would not have made had such questions not been posed, thus helping the reader to process the text at a deeper level.

\section{REFERENCES}

Beck, I. L., McKeown, M. G., Sinatra, G. M., \& Loxterman, J. A (1991). Revising social studies text from a text-processing perspective: Evidence of improved comprehensibility. Reading Research Quarterly, 26, 251-275.

BovaIR, S., \& KIERAS, D. E. (1985). A guide to propositional analysis for research on technical prose. In B. K. Britton \& J. B. Black (Eds.), Understanding expository text (pp. 315-362). Hillsdale, NJ: Erlbaum.

Britton, B. K., \& BLACK, J. B. (1985). Understanding expository text. Hillsdale, NJ: Erlbaum.

BRITTON, B. K., \& GÜLGÖz, S. (1991). Using Kintsch's computational model to improve instructional text: Effects of repairing inference calls on recall and cognitive structures. Journal of Educational Psychology, 83, 329-345.

Britton, B. K., Van Dusen, L., Glynn, S. M., \& Hemphill, D. (1990). The impact of inferences on instructional text. In A. C. Graesser \& G. H. Bower (Eds.), The psychology of learning and motivation (Vol. 25, pp. 53-70). San Diego: Academic Press.

Coulthard, M. (1994). Advances in written text analysis. London: Routledge.

Coulthard, M. (1997). An introduction to discourse analysis. Reading, MA: Addison-Wesley.

Ferst L, E. C., \& KinTsCH, W. (1998). Learning from text: Structural knowledge assessment in the study of discourse. In H. Van Oostenderp \& S. R. Goldman (Eds.), The construction of mental representations during reading (pp. 247-277). Mahwah, NJ: Erlbaum.

Gernsbacher, M. A. (1997). Two decades of structure building. Discourse Processes, 23, 265-304.

GoLDEN, R. M. (1998). Knowledge digraph contribution analysis of protocol data. Discourse Processes, 25, 179-210.

Goldman, S. R., Varma, S., \& CotÉ, N. (1996). Extending capacityconstrained construction integration: Toward "smarter" and flexible models of text comprehension. In B. K. Britton \& A. C. Graesser (Eds.), Models of understanding text (pp. 73-113). Mahwah, NJ: Erlbaum.

Graesser, A. C. (1981). Prose comprehension beyond the word. New York: Springer-Verlag.

Graesser, A. C., \& Goodman, S. H. (1985a). How to construct conceptual graph structures. In B. K. Britton \& J. B. Black (Eds.), Understanding expository text (pp. 363-383). Hillsdale, NJ: Erlbaum.

Graesser, A. C., \& Goodman, S. H. (1985b). Implicit knowledge, question answering, and the representation of expository text. In B. K. Britton \& J. B. Black (Eds.), Understanding expository text (pp. 109-171). Hillsdale, NJ: Erlbaum.

Graesser, A. C., Gordon, S., \& Brainerd, L. E. (1992). QUEST: A model of question answering. Computers \& Mathematics with Applications, 23, 733-745.

Graesser A. C., \& Hemphill, D. (1991). Question answering in the context of scientific mechanism. Journal of Memory \& Language, 30, $186-209$.

Graesser, A. C., Lang, K. L., \& Roberts, R. M. (1991). Question answering in the context of stories. Journal of Experimental Psychology: General, 120, 254-277.

Graesser, A. C., Singer, M., \& Trabasso, T. (1994). Constructing inference during narrative text comprehension. Psychological Review, 101, 371-395.

Graesser, A. C., Wiemer-Hastings, P., \& Wiemer-Hastings, K. (2001). Constructing inferences and relations during text comprehension. In T. Sanders, J. Schilperoord, \& W. Spooren (Eds.), Text representation: Linguistic and psycholinguistic aspects (pp. 249271). Amsterdam: Benjamins.

KINTSCH, W. (1974). The representation of meaning in memory. Hillsdale, NJ: Erlbaum.
KinTsch, W. (1998). Comprehension. A paradigm for cognition. Cambridge: Cambridge University Press.

KinTsch, W., \& VAN DiJK, T. A. (1978). Toward a model of text comprehension and production. Psychological Review, 85, 363-394.

Linderholm, T., Everson, M. G., van den Broek, P., Mischinski, M., Crittenden, A., \& Samuels, J. (2001). Effects of causal text revisions on more- and less-skilled reader's comprehension of easy and difficult texts. Cognition \& Instruction, 18, 525-556.

Linn, M., Songer, N. B., \& Eylon, B.-S. (1996). Shifts and convergences in science learning and instruction. In D. C. Berliner \& R. C. Calfee (Eds.), Handbook of educational psychology (pp. 438-490). New York: Macmillan

MacNeally, M. S., \& Hedges, K. (1996). The effects of line length on the psychological reality of the paragraph. In R. J. Kreuz \& M. S. MacNeally (Eds.), Empirical approaches to literature and aesthetics (pp. 99-123). Norwood, NJ: Ablex.

MANDleR, J. M., \& Johnson, N. S. (1977). Remembrance of things parsed: Story structure and recall. Cognitive Psychology, 9, 111-151.

MANNES, S., \& George, M. S. (1996). Effects of prior knowledge on text comprehension: A simple modeling approach. In B. K. Britton \& A. C. Graesser (Eds.), Models of understanding text (pp. 115-139). Mahwah, NJ: Erlbaum.

McNamara, D. S., Kintsch, E., Songer, N. S., \& Kintsch, W. (1996). Are good texts always better? Interactions of text coherence, background knowledge, and levels of understanding in learning from text. Cognition \& Instruction, 14, 1-43.

MeYer, B. J. F. (1975). The organization of prose and its effects on memory. Amsterdam: North-Holland.

Meyer, B. J. F. (1985). Prose analysis: Purposes, procedures and problems. In B. K. Britton \& J. B. Black (Eds.), Understanding expository text (pp. 11-64). Hillsdale, NJ: Erlbaum.

Miller, J. R., \& KintsCH, W. (1980). Readability and recall for short passages: A theoretical analysis. Journal of Experimental Psychology: Human Learning \& Memory, 6, 335-354

NaUghton, P., \& Schildt, H. (1997). JAVA: The complete reference. Berkeley, CA: Osborne McGraw-Hill.

PolanYI, L. (1988). A formal model of the structure of discourse. Journal of Pragmatics, 12, 601-638.

Rumelhart, D. E. (1977). Understanding and summarizing brief stories. In D. Laberge \& S. J. Samuels (Eds.), Basic processes in reading: Perceptions and comprehensions (pp. 265-304). Hillsdale, NJ: Erlbaum.

Rumelhart, D. E. (1980). Schemata: The building blocks of cognition. In R. J. Spiro, B. C. Bruce, \& W. F. Brewer (Eds.), Theoretical issues in reading comprehension (pp. 33-58). Hillsdale, NJ: Erlbaum.

SANDERS, T., \& VAN WIJK, C. (1996). PISA: A procedure for analyzing the structure of explanatory texts. Text, 16, 91-132.

Schank, R. C., \& ABElson, R. P. (1977). Scripts, plans, goals and understanding. Hillsdale, NJ: Erlbaum.

Stein, N. L., \& GLenN, G. G. (1979). An analysis of story comprehension in elementary school children. In R. O. Freedle (Ed.), New directions in discourse processing (Vol. 2, pp. 53-120). Norwood, NJ: Ablex.

ThORNDYKe, P. W. (1977). Cognitive structures in comprehension and memory of narrative discourse. Cognitive Psychology, 9, 77-110.

Trabasso, T., van den Broek, P. W., \& SuH, S. Y. (1989). Logical necessity and transitivity of causal relations in stories. Discourse Processes, 12, 1-25.

Turner, A., Britton, B. K., Andraessen, P., \& McCutchen, D. (1996). A predication semantic model of text comprehension and recall. In B. K. Britton \& A. C. Graesser (Eds.), Models of understanding text (pp. 33-71). Mahwah, NJ: Erlbaum.

VAN DiJK, T. A., \& KinTsch, W. (1983). Strategies of discourse comprehension. San Diego: Academic Press.

Vidal-Abarca, E., Gilabert, R, \& ABad, N. (2001). Context variables must be considered when replicating text coherence studies. Manuscript in preparation.

Vidal-Abarca, E., Martinez, G., \& Gilabert, R. (2000). Two procedures to improve instructional text: Effects on memory and learning. Journal of Educational Psychology, 92, 107-116.

VidAL-ABARCA, E., \& SANJosÉ, V. (1998). Levels of comprehension of scientific prose: The role of text variables. Learning \& Instruction, $\mathbf{8}, 215-233$. 
Vidal-Abarca, E., Sanjosé, V., Gilabert, R., \& Abad, N. (2001).Improving text coherence to enhance readers' inferences. Manuscript in preparation.

WinebURG, S. S. (1996). The psychology of learning and teaching history. In D. C. Berliner \& R. C. Calfee (Eds.), Handbook of educational psychology (pp. 423-437). New York: MacMillan.

Zwaan, R. A., Langston, M. C., \& Graesser, A. C. (1995). The construction of situation models in narrative comprehension: An eventindexing model. Psychological Science, 6, 292-297.

Zwaan, R. A., Magliano, J. P., \& Graesser, A. C. (1994). Dimensions of situation model construction in narrative comprehension. Journal of Memory \& Language, 21, 386-397.

\section{NOTE}

1. The division of the texts into nodes, reflected in Figures 6 and 7, does not correspond to the division of the texts into sentences carried out by Goldman et al. (1996) on pp. 90, 109, and 110. Some sentences from the text are divided into two independent nodes, following the rules already explained on the division of texts into nodes in ETAT.

(Manuscript received June 21, 2000;

revision accepted for publication August 4, 2001.) 